\section{RMD Open}

Rheumatic \& Musculoskeletal Diseases

\title{
Achieving comprehensive disease control in patients with early and established rheumatoid arthritis treated with adalimumab plus methotrexate versus methotrexate alone
}

Edward C Keystone, ${ }^{1}$ Ferdinand C Breedveld, ${ }^{2}$ Désirée van der Heijde, ${ }^{2}$ Ronald F van Vollenhoven, ${ }^{3,4}$ Paul Emery, ${ }^{5}$ Josef S Smolen, ${ }^{6,7}$ lain Sainsbury, ${ }^{8}$ Stefan Florentinus, ${ }^{9}$ Hartmut Kupper, ${ }^{10}$ Kun Chen, ${ }^{11}$ Arthur Kavanaugh ${ }^{12}$

To cite: Keystone EC, Breedveld FC, Heijde Dvder, et al. Achieving comprehensive disease control in patients with early and established rheumatoid arthritis treated with adalimumab plus methotrexate versus methotrexate alone. RMD Open 2017;3:e000445. doi:10.1136/ rmdopen-2017-000445

- Prepublication history and additional material for this paper are available online. To view please visit the journal (http://dx doi.org/10.1136/rmdopen-2017000445).

Received 25 January 2017 Revised 22 August 2017 Accepted 23 August 2017

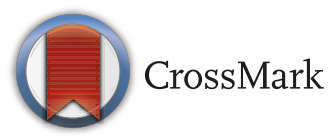

For numbered affiliations see end of article.

\section{Correspondence to} Dr Edward C Keystone, ; edkeystone@mtsinai.on.ca

\section{ABSTRACT}

Objective To evaluate the achievement of comprehensive disease control (CDC) following 1 year of treatment with adalimumab+methotrexate versus methotrexate alone and whether early achievement of remission (at week 24 or 26) is associated with CDC at week 52 in patients with either early or established rheumatoid arthritis (RA). Methods Post hoc analyses were conducted in three clinical studies assessing treatment with adalimumab+methotrexate: DE019 (NCT00195702) enrolled patients with established RA who were methotrexate inadequate responders; OPTIMA (NCT00420927) and PREMIER (NCT00195663) enrolled methotrexate-naive patients with early RA. In OPTIMA, patients not achieving stable low disease activity at weeks 22 and 26 in the placebo+methotrexate group could receive open-label adalimumab+methotrexate for 52 weeks (Rescue ADA arm). CDC was defined as the simultaneous achievement of clinical remission (DAS28 $(\mathrm{CRP})<2.6)$, normal function $(\mathrm{HAQ}-\mathrm{Dl}<0.5)$ and absence of radiographic progression ( $\triangle \mathrm{mTSS} \leq 0.5)$. Results Regardless of disease duration, significantly more patients receiving adalimumab+methotrexate achieved CDC compared with methotrexate alone. In the adalimumab+methotrexate group, a numerically greater proportion of patients with early RA $(\sim 25 \%)$ versus established RA (14\%) achieved CDC at 1 year; achievement of CDC was notably greater among patients who met criteria for remission at week 24 or $26(\sim 50 \%$ of patients with early RA and $39 \%$ with established RA).

Conclusion Treatment with adalimumab+methotrexate increases the likelihood of achieving CDC in patients with either early or established RA. Clinical remission at week 24 or 26 is associated with achievement of CDC at week 52.

Trial registration number DE019 (NCT00195702), OPTIMA (NCT00420927), PREMIER (NCT00195663); Post-results.

\section{INTRODUCTION}

Rheumatoid arthritis (RA) is a chronic and debilitating inflammatory disease with a population prevalence of approximately

\section{Key messages}

What is already known about this subject?

- Clinical remission is the primary goal of treating rheumatoid arthritis (RA); comprehensive disease control (CDC) additionally encompasses preservation of physical function and prevention of structural damage progression and is a realistic therapeutic goal in patients with early RA.

- It has been unclear whether achieving clinical remission can predict subsequent CDC.

What does this study add?

- In this analysis of three studies, clinical remission at 24 or 26 weeks was associated with achievement of CDC at 52 weeks.

- Combination treatment with adalimumab+methotrexate (vs methotrexate alone) increased the likelihood of achieving CDC in patients with either early or established RA.

How might this impact on clinical practice?

- These findings may help guide treatment decisions, including the utility of combination treatment in patients with early and established RA.

$1 \% .^{1}$ Progressive inflammation in the joints of patients can lead to irreversible joint damage $^{23}$ and diminished function and disability. ${ }^{4}$ The primary goal of treating RA is to achieve a target of clinical remission, thereby maximising quality of life. Early diagnosis and treatment are important for achieving the elements of comprehensive disease control (CDC), including normalisation of physical function, achievement of clinical remission or low disease activity (LDA) and absence of structural damage progression through effective suppression of inflammation. ${ }^{5-7}$ 
CDC is unlikely to be achievable in a large proportion of patients with established RA because of increasing functional impairment, ${ }^{8}$ although it should constitute a realistic therapeutic goal in patients with early RA as suggested by treat-to-target recommendations, ${ }^{6}$ systematic literature reviews ${ }^{9}{ }^{10}$ and clinical studies. ${ }^{11} 12$ Treatment recommendations suggest initial treatment of active disease with methotrexate (MTX) monotherapy; after 6 months of unsuccessful treatment, a biological disease-modifying antirheumatic drug (DMARD), such as a tumour necrosis factor (TNF) inhibitor, should be added to the therapy of patients with poor prognostic factors. ${ }^{13}$ Although there is evidence that early response or remission in RA is strongly predictive of subsequent long-term remission, ${ }^{14-16}$ it is not clear to what extent clinical remission of RA can predict subsequent achievement of CDC.

The post hoc analyses detailed in this report aim to (1) evaluate attainment of CDC after 1 year of treatment with the combination of adalimumab+MTX and (2) assess whether the achievement of clinical remission at week 24 or 26 is associated with CDC at week 52 in three randomised controlled trials in patients with early or established RA.

\section{PATIENTS AND METHODS \\ Patients}

Patient data originated from three randomised clinical trials in RA: DE019 (NCT00195702) ${ }^{17}$ PREMIER $\left(\right.$ NCT00195663) ${ }^{18}$ and OPTIMA (NCT00420927). ${ }^{19}{ }^{20}$ All of the studies enrolled adults aged $\geq 18$ years with a diagnosis of active RA as defined by the 1987 revised criteria of the American College of Rheumatology (formerly American Rheumatism Association). ${ }^{21}$ As noted in the original publications, an institutional review board or ethics committee approved the studies at each site. ${ }^{17-20}$

DE019 was a 1-year, phase 3, randomised, doubleblind, placebo-controlled trial of adalimumab in patients with RA who had active disease despite a minimum of 3 months of treatment with MTX (MTX inadequate response (MTX-IR)) at a stable weekly dose of $12.5-25 \mathrm{mg}$ (or $\geq 10 \mathrm{mg}$ /week in those intolerant to higher doses of MTX) for $\geq 4$ weeks. ${ }^{17}$ In addition, patients were required to have a swollen joint count based on 66 assessed joints (SJC66) $\geq 6$, tender joint count based on 68 assessed joints (TJC68) $\geq 9$, C-reactive protein (CRP) $\geq 1.0 \mathrm{mg}$ / $\mathrm{dL}$, and either had to be rheumatoid factor (RF) positive or have $\geq 1$ joint erosion on X-ray. Traditional DMARDs other than MTX were discontinued at least 28 days before baseline evaluations.

PREMIER was a 2-year, phase 3, randomised, doubleblind, active comparator-controlled trial of adalimumab in an MTX-naive population with RA disease duration $<3$ years. ${ }^{18}$ Patients were required to have SJC66 $\geq 8$, TJC68 $\geq 10$, either an erythrocyte sedimentation rate (ESR) of $\geq 28 \mathrm{~mm} /$ hour or $\mathrm{CRP} \geq 1.5 \mathrm{mg} / \mathrm{dL}$, and either had to be RF positive or have $\geq 1$ joint erosion on X-ray. Patients who had received treatment with
MTX, cyclophosphamide, cyclosporine, azathioprine or $>2$ other DMARDs were excluded.

OPTIMA (Optimal Protocol for Treatment Initiation with MTX and Adalimumab) was a 78-week, phase 4, double-blind, randomised, placebo-controlled trial of adalimumab in patients with early RA with a duration $<1$ year and moderate or high disease activity not previously treated with MTX. ${ }^{19} 20$ Patients were required to have SJC66 $\geq 6$, TJC68 $\geq 8$, either an ESR of $\geq 28 \mathrm{~mm}$ / hour or $\mathrm{CRP} \geq 1.5 \mathrm{mg} / \mathrm{dL}$, and either had to be RF positive, anticyclic citrullinated peptide positive, or have $>1$ joint erosion on X-ray. Patients who had received previous MTX or other biological treatment were excluded.

\section{Treatment regimens}

In DE019, patients were randomly assigned 1:1:1 to receive adalimumab $40 \mathrm{mg}$ subcutaneously every other week (with placebo injections on alternate weeks), adalimumab $20 \mathrm{mg}$ subcutaneously weekly (not included in this analysis) or placebo subcutaneously weekly. The patient's dose of concomitant MTX at baseline remained constant during the 52-week study; if toxicity occurred, the dose could be reduced to not lower than $10 \mathrm{mg}$ weekly.

In PREMIER, patients were randomised 1:1:1 to receive adalimumab $40 \mathrm{mg}$ subcutaneously every other week plus weekly oral MTX, adalimumab $40 \mathrm{mg}$ monotherapy every other week plus weekly placebo (not included in this analysis) or weekly MTX plus placebo. MTX therapy was initiated at a weekly dose of $7.5 \mathrm{mg}$ for the first 4 weeks of the study, $15 \mathrm{mg}$ weekly during weeks $4-8$, then $20 \mathrm{mg}$ weekly at week 9 .

In OPTIMA, patients were randomised 1:1 to receive adalimumab $40 \mathrm{mg}$ subcutaneously every other week plus weekly MTX, initiated at a dose of $7.5 \mathrm{mg}$ and rapidly titrated to $20 \mathrm{mg}$ by week 8 , or placebo plus MTX for 26 weeks (period 1). On the basis of achievement of a stable LDA target (28-joint Disease Activity Score based on CRP $($ DAS28(CRP) $) \leq 3.2$ at weeks 22 and 26), placebo+MTX patients not achieving stable LDA (MTX-IR patients) received open-label adalimumab+MTX during period 2 (Rescue ADA arm) for an additional 52 weeks. This analysis included patients in the Rescue ADA population who represent patients with early RA and MTX-IR.

\section{Clinical, functional and radiographic assessments of CDC}

CDC was considered the simultaneous achievement of (1) clinical remission, (2) normal physical function and (3) absence of radiographic progression. Clinical signs and symptoms of inflammation were assessed with the DAS28(CRP) or its components. The DAS28(CRP) is composed of four outcome variables: TJC and SJC (each based on 28-joint assessment), CRP and patient's global assessment of disease activity on a visual analogue scale (VAS; $0-10 \mathrm{~cm}) .{ }^{22}$ Clinical remission was defined as DAS28(CRP) $<2.6$ (OPTIMA and PREMIER trials). ${ }^{182023-25}$ Additional post hoc analyses used the Simplified Disease Activity Index (SDAI), which is the sum of five outcome variables: TJC and SJC (each based on 28-joint assessment), patient and physician global 
assessment of disease activity (VAS $0-10 \mathrm{~cm}$ ) and CRP; a score of $\leq 3.3$ indicates remission. ${ }^{25}{ }^{26}$ In patients with established RA (DE019 trial), achievement of LDA (defined as DAS28(CRP) $\leq 3.2)^{2327} 28$ rather than remission was used to define the clinical assessment component of CDC.

Physical function was assessed using the Health Assessment Questionnaire Disability Index (HAQ-DI; score range, 0-3). ${ }^{29}$ Normal physical function was defined as HAQ-DI $<0.5 .^{30}{ }^{31}$ To quantify structural joint damage, radiographs of the hands/wrists and feet were obtained and scored using the modified total Sharp score (mTSS) method. ${ }^{32-34}$ Radiographic progression of structural joint damage was assessed as the change from baseline (or from week 24/26) in mTSS ( $\Delta$ mTSS). Absence of radiographic progression was defined as $\Delta \mathrm{mTSS} \leq 0.50 .^{35}$

\section{Statistical analyses}

The intent-to-treat population included all patients who were randomised and received $\geq 1$ dose of study drug. These post hoc analyses assessed the proportion of patients achieving CDC as well as its individual components following 1 year of treatment with adalimumab+MTX or placebo+MTX in DE019 and PREMIER, and open-label adalimumab+MTX in the Rescue ADA arm of OPTIMA. To explore which component may be a limiting factor to achievement of CDC, frequencies of patients achieving DAS28(CRP) $<2.6$ (or DAS28(CRP) $\leq 3.2$ ), HAQ-DI $<0.5$, or $\Delta \mathrm{mTSS} \leq 0.5$, and combinations of the targets were determined.

Last observation carried forward (LOCF) was used to replace missing clinical and functional data for patients with postbaseline assessments; non-responder imputation (NRI) was used for patients without any postbaseline assessments. Missing Sharp scores were imputed by linear extrapolation for patients with baseline and postbaseline X-rays. Patients without a postbaseline X-ray were considered as showing radiographic progression. Sensitivity analyses for radiographic non-progression and CDC (DAS28 (CRP $<2.6$ or $\leq 3.2)$, HAQ-DI $<0.5$ and $\Delta$ mTSS $\leq 0.5$ ) based on observed data and LOCF and NRI data excluding patients without any postbaseline assessment were used to assess the effect of missing data.

Logistic regression was used to assess the treatment effect on radiographic non-progression and CDC based on $\mathrm{DAS} 28(\mathrm{CRP})<2.6$ or $\leq 3.2$. Generalised estimating equation was used to model the time-repeated measurement of LDA, remission and normal function. Fisher's exact test was used to assess treatment effect on CDC based on $\mathrm{SDAI}<3.3$. There was no adjustment for multiple testing. Venn diagramming was used to display the percentages of the combination of clinical remission or LDA (yes/no), normal function (yes/no) and radiographic non-progression (yes/no) for CDC.

\section{RESULTS}

Baseline characteristics: overall study populations

Baseline demographics and disease characteristics for patients receiving adalimumab+MTX or placebo+MTX in DE019 and PREMIER were indicative of patients with established and early, active RA, respectively (table 1 ). Despite an inadequate response to MTX at month 6 , the majority of patients in the Rescue ADA arm of OPTIMA were in a moderate disease activity state at the time of open-label adalimumab initiation.

Achievement of CDC at 1 year: overall patient populations In MTX-IR patients with established RA (DE019), CDC based on DAS28(CRP) $<2.6$ was achieved in $14 \%$ (n/ $\mathrm{N}=28 / 207$ ) of patients in the adalimumab+MTXarm compared with $3 \%(\mathrm{n} / \mathrm{N}=5 / 200)$ in the placebo+MTXarm $(\mathrm{p}<0.001)$; CDC based on $\mathrm{SDAI} \leq 3.3$ was achieved in 5\% (n/N=11/207) and 2\% (n/N=4/207), respectively (figure $1 \mathrm{~A})$. When LDA (DAS28(CRP) $\leq 3.2$ ) was used for this population of patients with established disease, $19 \%(\mathrm{n} / \mathrm{N}=40 / 207)$ of patients receiving adalimumab+MTX achieved a CDC state at 1 year versus $5 \%(\mathrm{n} / \mathrm{N}=10 / 200)$ of patients receiving placebo $+\mathrm{MTX}$ $(\mathrm{p}<0.001$ and $\mathrm{p}=0.45$; figure $1 \mathrm{~A})$.

In patients with early RA (PREMIER), CDC based on DAS28(CRP) $<2.6$ was achieved in $25 \%(\mathrm{n} / \mathrm{N}=67 / 268)$ of patients in the adalimumab+MTXarm compared with $9 \%(\mathrm{n} / \mathrm{N}=22 / 257)$ in the placebo+MTXarm $(\mathrm{p}<0.001$; figure 1B). Similarly, in patients with early aggressive RA who had inadequate response to MTX during the first 6 months of therapy with placebo+MTX (OPTIMA), CDC was achieved in 24\% ( $/ \mathrm{N}=82 / 348)$ of patients after 1 year of open-label adalimumab+MTX treatment (figure 1C). Similar trends were observed when CDC was based on LDA or SDAI remission (figure 1B,C).

Consistent with the comparative treatment data for CDC in DE019 and PREMIER, a greater percentage of patients in the adalimumab+MTX arms achieved each of the individual components for CDC (online supplementary figures 1 and 2). In the OPTIMA study, open-label adalimumab+MTX resulted in rapid improvements in clinical and functional components, with normal function being the more difficult target to reach (online supplementary figure 3 ).

\section{Responder analysis: achievement of CDC and individual components}

Post hoc analysis examining the frequency of responders to individual components of $\mathrm{CDC}$ (with the clinical component of remission based on DAS28 $($ CRP $)<2.6)$ is presented in Venn diagrams (figure 2). In addition to patients who achieved CDC by this definition, 6\% (n/ $\mathrm{N}=13 / 207$ ) of patients in the adalimumab+MTXarm satisfied the remission and radiographic non-progression criteria at year 1 vs $2 \%(\mathrm{n} / \mathrm{N}=3 / 200)$ of patients in the placebo+MTX arm in the DE019 study; an additional $2 \%(\mathrm{n} / \mathrm{N}=5 / 207)$ and $1 \%(\mathrm{n} / \mathrm{N}=2 / 200)$ of patients in each treatment arm, respectively, also satisfied the remission and normal function criteria (figure $2 \mathrm{~A}, \mathrm{~B}$ ). In the PREMIER study, an additional $10 \%(\mathrm{n} / \mathrm{N}=28 / 268)$ of patients in the adalimumab+MTXarm and 10\% (n/ $\mathrm{N}=25 / 257)$ in the placebo+MTX arm achieved remission and normal function criteria, and $7 \%(\mathrm{n} / \mathrm{N}=19 / 268)$ 
Table 1 Baseline demographics and disease characteristics

\begin{tabular}{|c|c|c|c|c|c|}
\hline \multirow[b]{2}{*}{ Characteristic $^{*}$} & \multicolumn{2}{|c|}{ DE019 (MTX-IR) } & \multicolumn{2}{|c|}{ PREMIER (MTX-naive) } & \multirow{2}{*}{$\begin{array}{l}\text { OPTIMA (MTX-IR†) } \\
\begin{array}{l}\text { Rescue ADA } \\
(\mathrm{n}=348)\end{array}\end{array}$} \\
\hline & $\begin{array}{l}\text { ADA+MTX } \\
(n=207)\end{array}$ & $\begin{array}{l}\text { PBO+MTX } \\
(n=200)\end{array}$ & $\begin{array}{l}\text { ADA+MTX } \\
(n=268)\end{array}$ & $\begin{array}{l}\text { PBO+MTX } \\
(n=257)\end{array}$ & \\
\hline Age, year & $56.1(13.5)$ & $56.1(12.0)$ & $51.9(14.0)$ & $52.0(13.1)$ & $51.2(13.9)$ \\
\hline Female, n (\%) & $158(76)$ & $146(73)$ & $193(72)$ & $190(74)$ & $266(76)$ \\
\hline $\begin{array}{l}\text { Rheumatoid factor positive, } \\
\mathrm{n}(\%)\end{array}$ & $168(81)$ & $179(90)$ & $228(85)$ & $215(84)$ & $274(79)$ \\
\hline Duration of RA, year & $11.0(9.2)$ & $10.9(8.8)$ & $0.7(0.8)$ & $0.8(0.9)$ & $0.8(0.3)$ \\
\hline Prior DMARD use, n (\%) & $207(100)$ & $200(100)$ & $87(33)$ & $81(32)$ & $348(100)$ \\
\hline Prior MTX dose, mg/week & $17.4(9.5)$ & $16.8(4.2)$ & 0 & 0 & $19.4(2.5)$ \\
\hline Corticosteroid use, n (\%) & $90(43)$ & $99(50)$ & $96(36)$ & $91(35)$ & $149(43)$ \\
\hline Corticosteroid dose, mg/day & $3.0(5.8)$ & $2.6(6.0)$ & $6.9(2.5)$ & $6.8(3.7)$ & $6.4(2.2)$ \\
\hline $\begin{array}{l}\text { DAS28(CRP) } \\
\text { (range, 0-10) }\end{array}$ & $5.6(0.9)$ & $5.8(0.9)$ & $6.3(0.9)$ & $6.3(0.9)$ & $4.5(1.2)$ \\
\hline DAS28(CRP) $\geq 5.1, \mathrm{n}(\%)$ & $150(73)$ & $155(78)$ & $230(89)$ & $235(94)$ & $111(32)$ \\
\hline CRP, mg/dL & $1.8(2.3)$ & $1.8(2.1)$ & $3.9(4.2)$ & $4.0(4.0)$ & $1.3(2.2)$ \\
\hline SJC (0-66 joints) & $19.3(9.8)$ & $19.0(9.5)$ & $21.1(11.2)$ & $22.1(11.7)$ & $9.4(9.2)$ \\
\hline TJC (0-68 joints) & $27.3(12.7)$ & $28.1(13.8)$ & $30.7(14.2)$ & $32.3(14.3)$ & $16.8(14.7)$ \\
\hline HAQ-DI (range, 0-3) & $1.5(0.6)$ & $1.5(0.6)$ & $1.5(0.6)$ & $1.5(0.7)$ & $1.1(0.6)$ \\
\hline mTSS (range, 0-398) & $72.1(60.7)$ & $66.4(47.4)$ & $18.1(20.1)$ & $21.9(22.2)$ & $13.0(19.5)$ \\
\hline JE (range, 0-230) & $41.4(33.4)$ & $37.2(25.8)$ & $11.0(12.3)$ & $13.6(13.6)$ & $5.9(9.3)$ \\
\hline JSN (range, 0-168) & $30.7(29.2)$ & $29.2(24.5)$ & $7.1(9.6)$ & $8.2(10.7)$ & $7.1(11.6)$ \\
\hline
\end{tabular}

${ }^{*}$ All values are mean (SD), unless otherwise indicated.

†OPTIMA enrolled MTX-naive patients; the Rescue ADA arm included patients treated with placebo+MTX who did not achieve stable low disease activity (ie, MTX-IR patients) at week 22 or 26, and received open-label ADA+MTX for an additional 52 weeks.

ADA, adalimumab; CRP, C-reactive protein; DAS28(CRP), 28-joint Disease Activity Score based on CRP; DMARD, (non-biological) diseasemodifying antirheumatic drug; HAQ-DI, Health Assessment Questionnaire Disability Index; IR, inadequate response; JE, joint erosion; JSN, joint space narrowing; mTSS, modified total Sharp score; MTX, methotrexate; PBO, placebo; RA, rheumatoid arthritis; SJC, swollen joint count; TJC, tender joint count.

and $2 \%(\mathrm{n} / \mathrm{N}=4 / 257)$, respectively, achieved remission and radiographic non-progression criteria at year 1 (figure 2C,D). Finally, in the OPTIMA study, an additional $16 \%(\mathrm{n} / \mathrm{N}=54 / 348)$ satisfied the remission and radiographic non-progression criteria and $3 \%$ (n/ $\mathrm{N}=10 / 348$ ) achieved remission and normal function criteria at year 1 (figure 2E). More patients achieved the clinical component of CDC when using DAS28(CRP) $\leq 3.2$ (online supplementary figure 4) and fewer patients achieved the clinical component when using $\mathrm{SDAI} \leq 3.3$ (figure 3), shifting the distribution of responses.

\section{Characteristics of patients achieving remission at week 24 or 26}

In the comparative studies (PREMIER (MTX-naive) and DE019 (MTX-IR)), patients receiving adalimumab+MTX were significantly more likely to achieve clinical remission at 24 or 26 weeks based on DAS28(CRP) $<2.6$ than patients receiving placebo+MTX (table 2). A comparison of remission criteria revealed that at week 24 or 26, more patients achieved a DAS28(CRP) score $<2.6$ than SDAI $\leq 3.3$ in all three studies (table 2). In line with previous observations, the mean values for DAS28(CRP),
mTSS and HAQ-DI for patients in clinical remission at 6 months were generally slightly higher for patients classified as being in remission by DAS28(CRP) versus SDAI criteria, but this did not reach statistical difference.

Achievement of CDC at 1 year: patients meeting criteria for remission at week 24 or 26

In the DE019 study, 39\% of patients in the adalimumab+MTXarm and 33\% in the placebo+MTXarm who met criteria for remission (DAS28 (CRP) $<2.6)$ at week 24 achieved CDC at 1 year (figure $4 \mathrm{~A}$ ) versus $14 \%$ and $3 \%$ in the overall population (figure 1A). Assessing individual components of CDC, a numerically greater proportion of patients achieved DAS28(CRP) $<2.6$ and $\Delta$ mTSS $\leq 0.5$ with adalimumab+MTX compared with placebo+MTX; however, achievement of HAQ-DI $<0.5$ was comparable between the treatment groups. In the PREMIER study, approximately $50 \%$ of patients who met criteria for remission at week 26 achieved CDC at 1 year, regardless of treatment arm (vs $25 \%$ and $9 \%$ in the overall population; figures $1 \mathrm{~B}$ and $4 \mathrm{~B}$ ). A numerically greater percentage of patients receiving adalimumab+MTX achieved DAS28(CRP) $<2.6$, whereas achievement of the other components of CDC was comparable between groups 
A

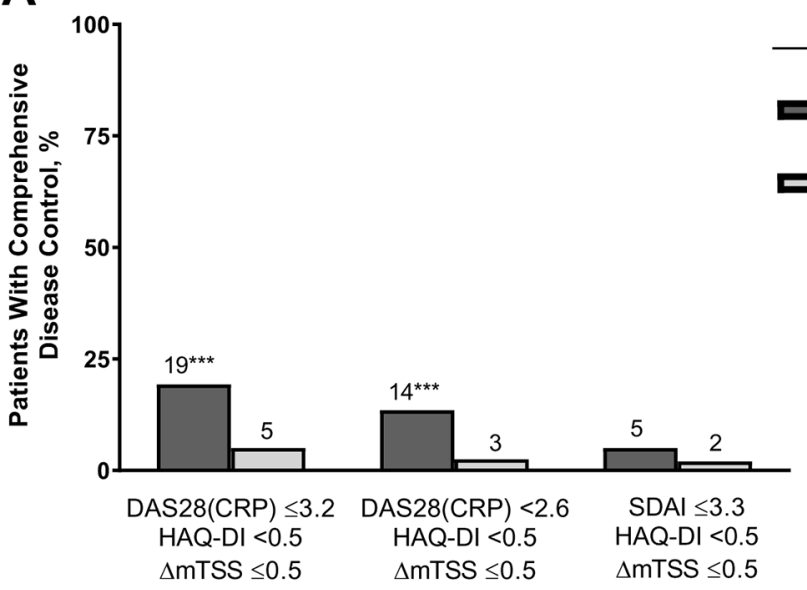

MTX-IR

$A D A+\operatorname{MTX}(n=207)$

a $\mathrm{PBO}+\operatorname{MTX}(\mathrm{n}=200)$

B

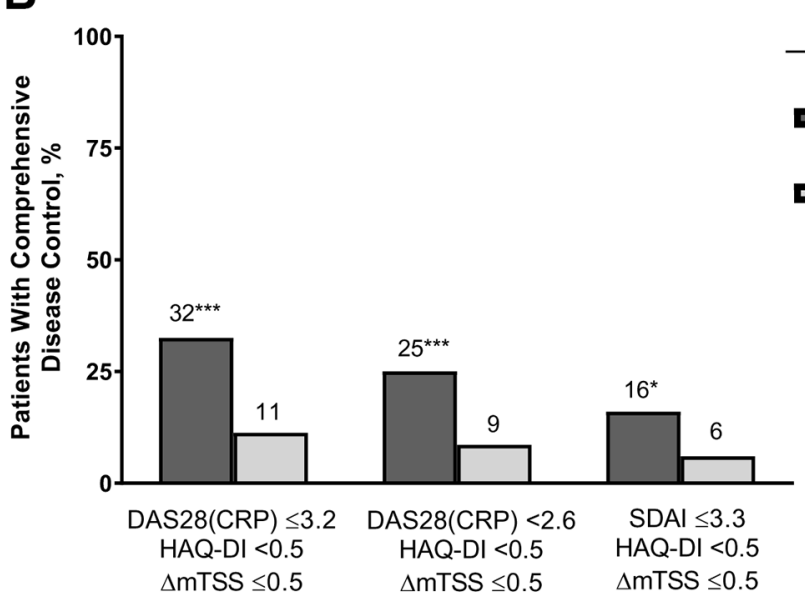

MTX naive

a $\mathrm{ADA}+\operatorname{MTX}(\mathrm{n}=268)$

ص $\mathrm{PBO}+\operatorname{MTX}(n=257)$

C

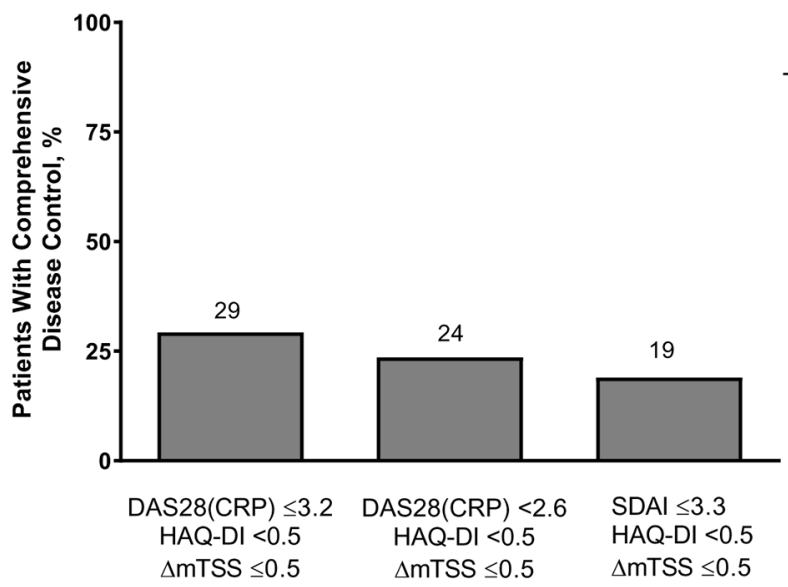

MTX-IR

ב $\operatorname{ADA}+\operatorname{MTX}(n=348)$

Figure 1 Percentage of patients achieving comprehensive disease control based on DAS28(CRP) $\leq 3.2$, DAS28(CRP) $<2.6$ or SDAI $\leq 3.3$ at week 52 in (A) DE019, (B) PREMIER and (C) the Rescue ADA arm of OPTIMA. ADA, adalimumab; DAS28(CRP), 28-joint Disease Activity Score based on C-reactive protein; HAQ-DI, Health Assessment Questionnaire Disability Index; IR, inadequate response; $\triangle \mathrm{mTSS}$, change in modified total Sharp score; MTX, methotrexate; PBO, placebo; SDAI, Simplified Disease Activity Index. ${ }^{*} p<0.05$ from Fisher's exact test, $A D A+M T X$ versus $P B O+M T X .{ }^{* \star} p<0.001$ from generalised estimating equation or logistic regression, ADA+MTXversus PBO+MTX. 
A $\quad$ ADA + MTX (MTX-IR)

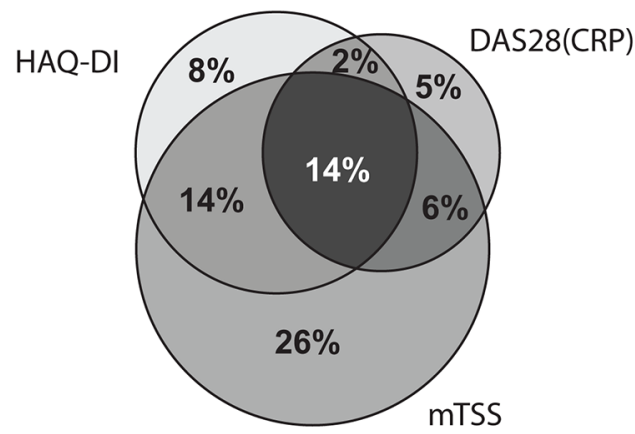

C $\quad$ ADA + MTX (MTX-naive)

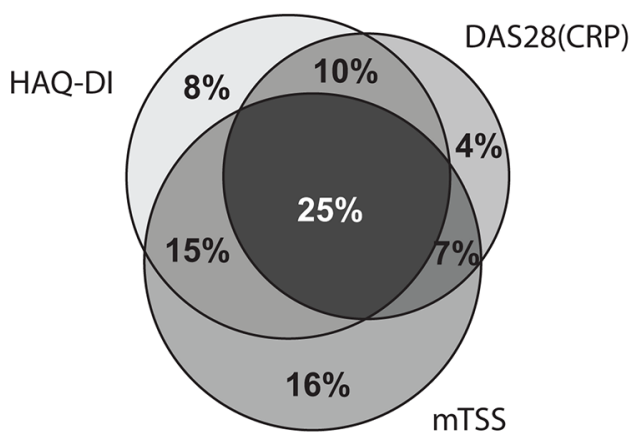

B $\quad \mathrm{PBO}+\mathrm{MTX}$ (MTX-IR)

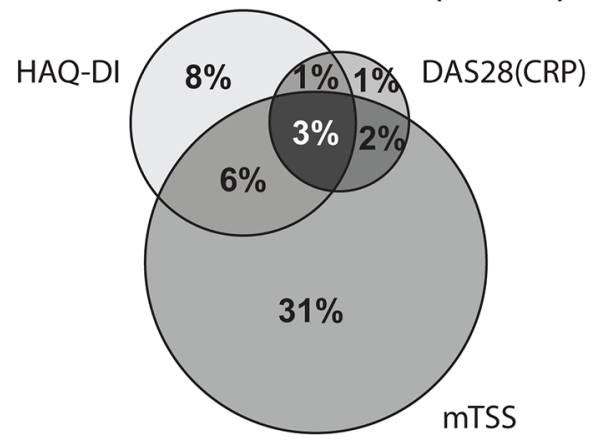

D $\quad \mathrm{PBO}+\mathrm{MTX}$ (MTX-naive)

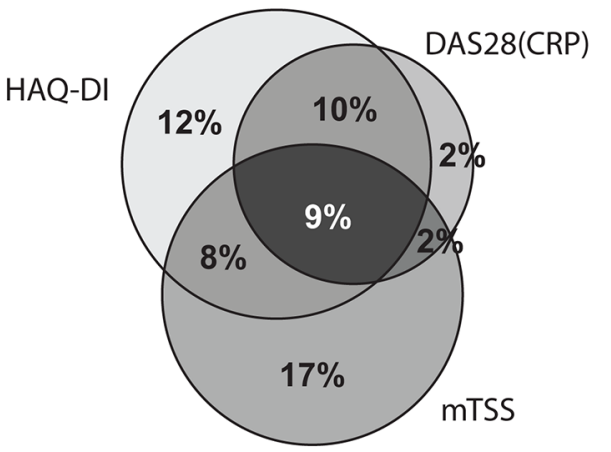

E $\quad A D A+M T X$ (MTX-IR)

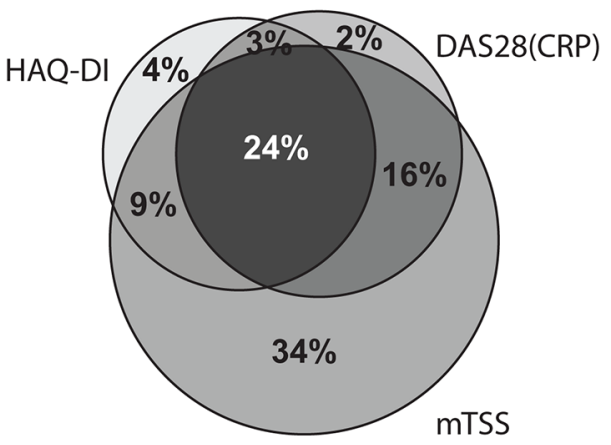

Figure 2 Frequency of responders to each CDC criterion (DAS28(CRP) $<2.6, \mathrm{HAQ}-\mathrm{DI}<0.5$ and $\triangle \mathrm{mTSS} \leq 0.5)$ at week 52 based on study treatments (A) DE019, ADA+MTX; (B) DE019, PBO+MTX; (C) PREMIER, ADA+MTX; (D) PREMIER, PBO+MTX; and (E) OPTIMA, open-label ADA+MTX (Rescue ADA arm). ADA, adalimumab; CDC, comprehensive disease control; DAS28(CRP), 28-joint Disease Activity Score based on C-reactive protein; HAQ-DI, Health Assessment Questionnaire Disability Index; IR, inadequate response; $\triangle \mathrm{mTSS}$, change in modified total Sharp score; MTX, methotrexate; PBO, placebo.

(figure 4B). In the open-label phase of OPTIMA, approximately $50 \%$ of patients who met criteria for remission at week 26 achieved CDC at 1 year (vs $24 \%$ in the overall population; figure 1C), with radiographic non-progression noted in approximately $90 \%$ of patients (figure 4C).

When remission was defined by $\mathrm{SDAI} \leq 3.3$, findings were generally comparable, although the proportion of patients achieving CDC was somewhat higher in each of the studies (figure 4). Additionally, to increase the sample size of patients with established RA (DE019), another analysis was conducted using
LDA as the clinical criterion at week 24 (ie, $n=46$ with DAS28 (CRP) $<2.6$ vs $n=82$ with DAS28 (CRP) $\leq 3.2$ ) and found that the percentage of patients achieving CDC at week 52 was reduced for both treatment groups (online supplementary figure 5).

In each of the studies, a closer examination of radiographic data among patients who achieved DAS28(CRP) $<2.6$ at week $24 / 26$ found that the mean $\triangle$ mTSS from week $24 / 26$ to week 52 was small (online supplementary figure 6). Notably, a subgroup of patients in all treatment 
A $\quad$ ADA + MTX (MTX-IR)

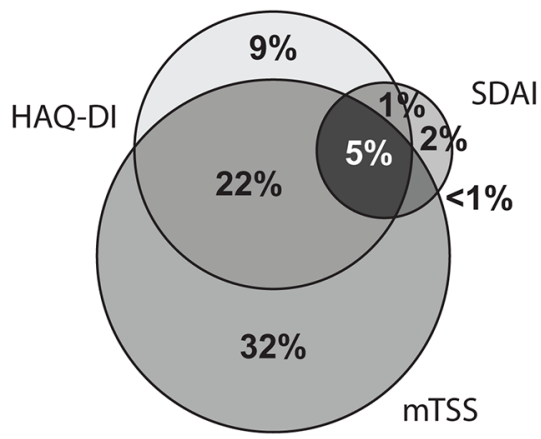

C ADA + MTX (MTX-naive)

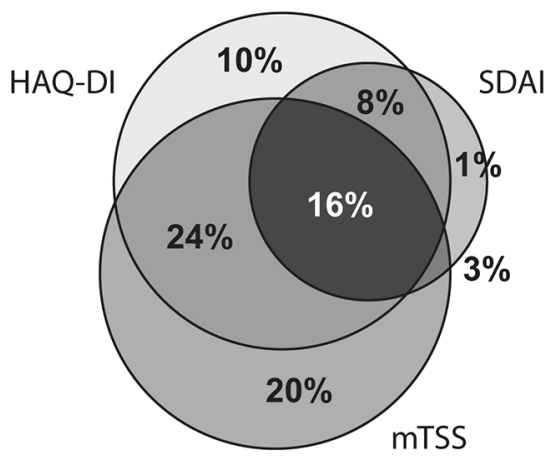

B $\quad \mathrm{PBO}+\mathrm{MTX}(\mathrm{MTX}-\mathrm{IR})$

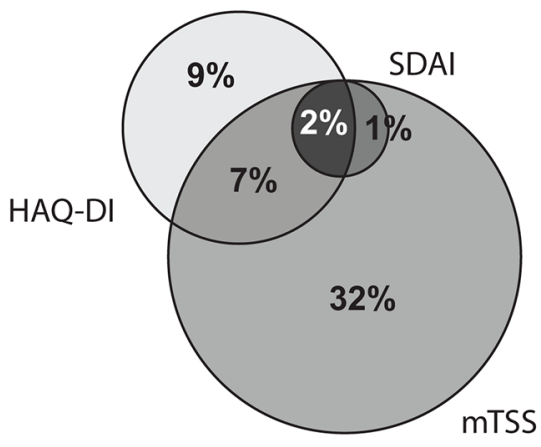

D $\quad \mathrm{PBO}+\mathrm{MTX}$ (MTX-naive)

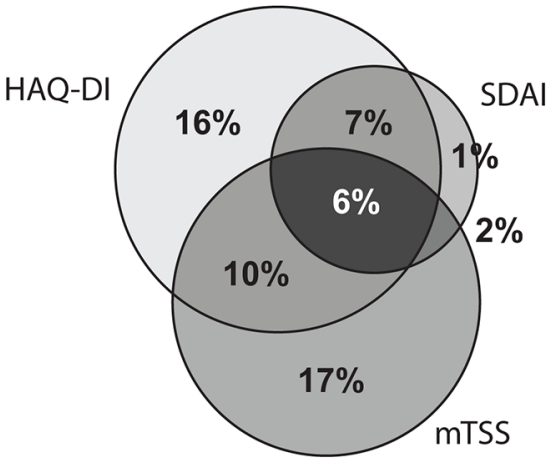

E $\quad$ ADA + MTX (MTX-IR)

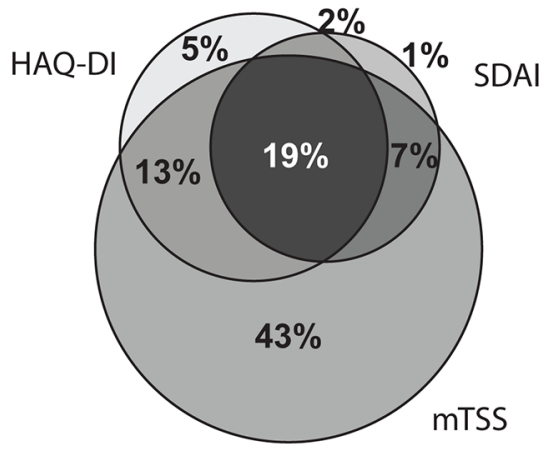

Figure 3 Frequency of responders to each $\mathrm{CDC}$ criterion (SDAl $\leq 3.3, \mathrm{HAQ}-\mathrm{DI}<0.5$ and $\triangle \mathrm{mTSS} \leq 0.5$ ) at week 52 based on study treatments (A) DE019, ADA+MTX; (B) DE019, PBO+MTX; (C) PREMIER, ADA+MTX; (D) PREMIER, PBO+MTX; and (E) OPTIMA, open-label ADA+MTX (Rescue ADA arm). ADA, adalimumab; CDC, comprehensive disease control; HAQ-DI, Health Assessment Questionnaire Disability Index; IR, inadequate response; $\triangle \mathrm{mTSS}$, change in modified total Sharp score; MTX, methotrexate; PBO, placebo; SDAI, Simplified Disease Activity Index.

groups showed rapid radiographic progression (ie, $\Delta$ mTSS $\geq 1.5$ ) between week $24 / 26$ and week 52 , with small differences between the treatment groups in early RA and larger differences in favour of combination therapy in established RA. Specifically, $14 \%$ of patients receiving adalimumab+MTX $(n=44)$ had progression at week 52 vs $22 \%$ of patients receiving placebo+MTX $(n=9)$ in DE019; for PREMIER, percentages were $14 \%(\mathrm{n}=98)$ vs $17 \%$ $(n=47)$, respectively. In OPTIMA, $5 \%$ of patients receiving adalimumab+MTX $(\mathrm{n}=120)$ had progression at week 52 .

\section{DISCUSSION}

These post hoc analyses of the DE019, PREMIER and OPTIMA studies found that significantly higher rates of CDC were observed following 1 year of treatment with 
Table 2 Patients in clinical remission at week 24/26 based on DAS28(CRP) $<2.6$ or SDAl $\leq 3.3$

\begin{tabular}{|c|c|c|c|c|}
\hline & \multicolumn{2}{|c|}{ DAS28(CRP) $<2.6$} & \multicolumn{2}{|l|}{ SDAI $\leq 3.3$} \\
\hline & ADA+MTX & PBO+MTX & ADA+MTX & PBO+MTX \\
\hline DE019 (MTX-IR) & $n=202$ & $n=191$ & $n=202$ & $n=191$ \\
\hline Proportion in remission at week 24 & $23 \%$ & $5 \% *$ & $10 \%$ & $2 \% *$ \\
\hline $\begin{array}{l}\text { Characteristics of patients in remission at week } \\
24 \text {, mean (SD) }\end{array}$ & $\mathrm{n}=46$ & $n=9$ & $n=21$ & $\mathrm{n}=4$ \\
\hline DAS28(CRP) & $2.11(0.33)$ & $2.06(0.40)$ & $1.88(0.32)$ & $1.65(0.08)$ \\
\hline mTSS & $57.4(58.1)$ & $41.4(26.8)$ & $45.2(46.7)$ & $41.6(33.2)$ \\
\hline HAQ-DI & $0.40(0.45)$ & $0.51(0.68)$ & $0.33(0.41)$ & $0.50(0.84)$ \\
\hline PREMIER (MTX-naive) & $n=267$ & $n=252$ & $n=267$ & $n=252$ \\
\hline Proportion in remission at week 26 & $37 \%$ & $19 \%{ }^{*}$ & $23 \%$ & $12 \%^{* *}$ \\
\hline $\begin{array}{l}\text { Characteristics of patients in remission at week } \\
26, \text { mean (SD) }\end{array}$ & $\mathrm{n}=98$ & $\mathrm{n}=48$ & $\mathrm{n}=62$ & $n=31$ \\
\hline DAS28(CRP) & $1.95(0.35)$ & $2.00(0.35)$ & $1.78(0.29)$ & $1.82(0.27)$ \\
\hline mTSS & $17.2(19.4)$ & $23.1(24.9)$ & $15.5(17.0)$ & $21.9(28.6)$ \\
\hline HAQ-DI & $0.25(0.40)$ & $0.22(0.35)$ & $0.18(0.28)$ & $0.18(0.36)$ \\
\hline OPTIMA (MTX-IR†) & $n=348$ & NA & $\mathrm{n}=348$ & NA \\
\hline Proportion in remission at week 26 & $34 \%$ & NA & $18 \%$ & NA \\
\hline $\begin{array}{l}\text { Characteristics of patients in remission at week } \\
26, \text { mean (SD) }\end{array}$ & $n=120$ & NA & $n=61$ & NA \\
\hline DAS28(CRP) & $2.0(0.37)$ & NA & $1.71(0.27)$ & NA \\
\hline mTSS & $13.4(19.9)$ & NA & $14.9(23.3)$ & NA \\
\hline HAQ-DI & $0.47(0.50)$ & NA & $0.31(0.40)$ & NA \\
\hline
\end{tabular}

${ }^{*} p<0.0001$ and ${ }^{* *} p=0.001$ vs ADA+MTX, Fisher's exact test; the last observation carried forward method was used to impute missing data for patients with postbaseline DAS28(CRP).

†OPTIMA enrolled MTX-naive patients; the Rescue ADA arm included patients treated with placebo+MTX who did not achieve stable low disease activity (ie, MTX-IR patients) at week 22 or 26, and received open-label ADA+MTX for an additional 52 weeks.

ADA, adalimumab; DAS28(CRP), 28-joint Disease Activity Score based on C-reactive protein; HAQ-DI, Health Assessment Questionnaire Disability Index; IR, inadequate response; mTSS, modified total Sharp score; MTX, methotrexate; NA, not applicable; PBO, placebo; SDAI, Simplified Disease Activity Index.

the combination of adalimumab+MTX than with placebo+MTX in MTX-IR patients with established RA and in patients with early RA who were MTX-naive. Overall, a numerically greater percentage of patients with early RA in PREMIER and OPTIMA met the criteria for clinical remission than patients with established RA in the DE019 study. Notably, a numerically greater percentage of patients who were in clinical remission at 24 or 26 weeks achieved CDC at 1 year versus patients in the overall population.

Given the clinical, functional and radiographic non-progression efficacy demonstrated by anti-TNFs plus MTX compared with MTX alone in patients with active RA, ${ }^{18} 203637$ the finding that patients treated with adalimumab+MTX had better outcomes than those receiving MTX alone in both early and established RA is not surprising; however, the combination of these outcomes (ie, CDC) had not been previously assessed.

As might be expected in more advanced disease, CDC was achieved in a relatively low number of patients with established RA compared with patients with early RA. Achievement of CDC in patients with established RA was mostly limited by achievement of DAS28(CRP) $<2.6$ or $\mathrm{SDAI} \leq 3.3$ as the clinical component criterion (figure 2 and 3), whereas HAQ-DI was the limiting factor when CDC was based on DAS28(CRP) $\leq 3.2$ (online supplementary figure 4). Based on the responder analysis, clinical remission was also identified as the chief limiting factor for achieving CDC (using DAS28(CRP) $<2.6$ as the clinical component criterion) in patients with early RA in the PREMIER study, whereas achievement of normal physical function was limiting for patients with early RA in the OPTIMA study. In contrast, achieving CDC using $\mathrm{SDAI} \leq 3.3$ as the clinical component criterion was the limiting factor in both PREMIER and OPTIMA, showing that the SDAI has a more stringent definition of remission than the DAS28(CRP). This is consistent with previous reports ${ }^{38} 39$ and aligns with proposals to change the cut-off values defining remission and LDA for DAS28(CRP) because the currently used values are too lenient. ${ }^{40}$ However, despite differences in disease activity level classifications, associations of SDAI and DAS28(CRP) remission criteria with functional status and joint damage progression show high accordance. ${ }^{38} 39$ 
A

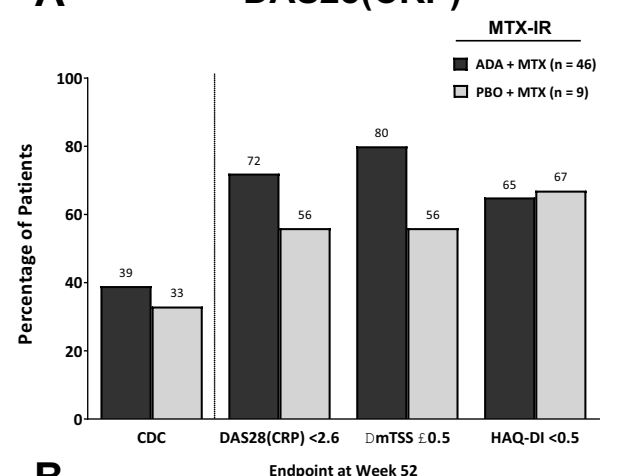

B
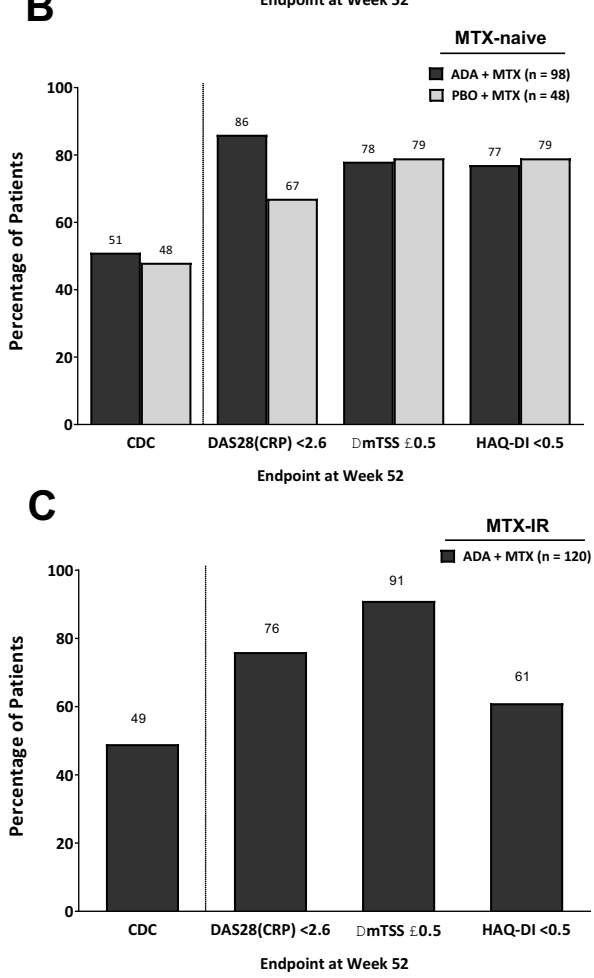

SDAI

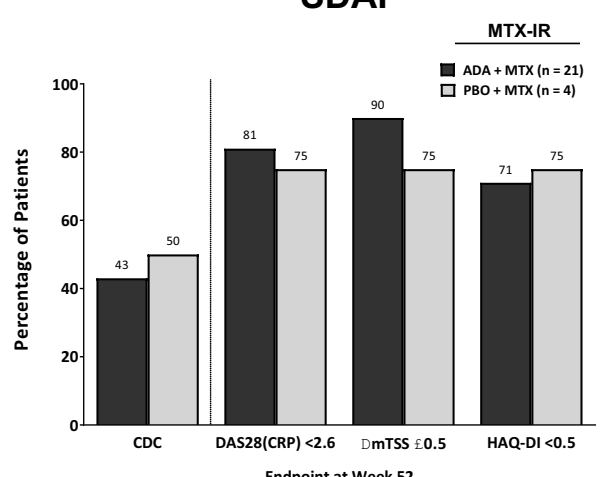

Endpoint at Week 52
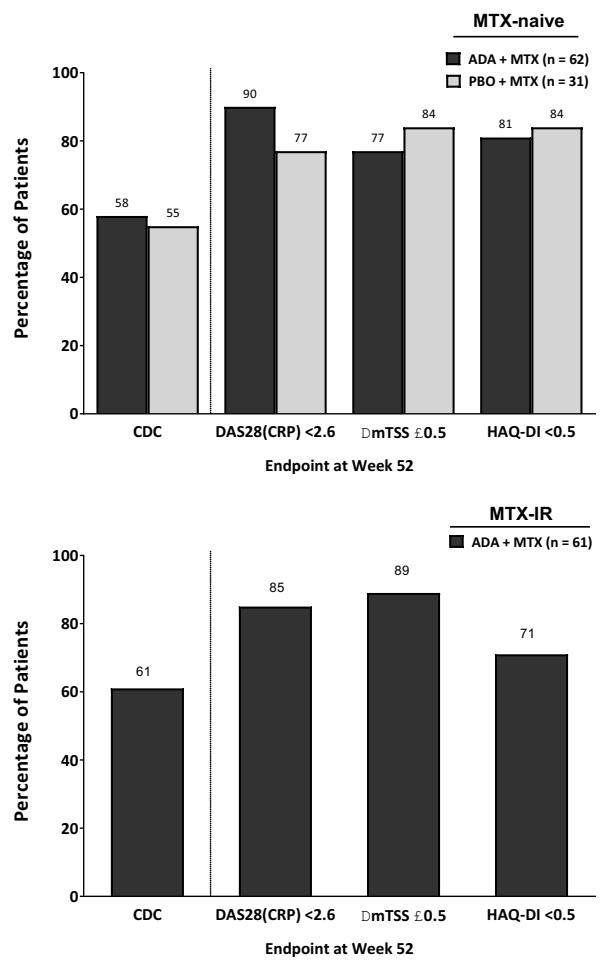

Figure 4 Percentage of patients with RA achieving DAS28(CRP) $<2.6$ (left panel) or SDAl $\leq 3.3$ (right panel) at week 24 or 26 who subsequently met criteria for $\mathrm{CDC}$, clinical remission, non-progression of joint damage or normal physical function at week 52 in (A) DE019, (B) PREMIER and (C) the Rescue ADA arm of OPTIMA. The last observation carried forward imputation method was used for patients with missing DAS28(CRP) and HAQ-DI data. Linear extrapolation was conducted for patients with missing mTSS data. The non-responder imputation method was used for patients without any postbaseline DAS28(CRP), HAQ-DI or mTSS data. ADA, adalimumab; CDC, comprehensive disease control; DAS28(CRP), 28-joint Disease Activity Score based on C-reactive protein; HAQ-DI, Health Assessment Questionnaire Disability Index; IR, inadequate response; $\triangle \mathrm{mTSS}$, change in modified total Sharp score; MTX, methotrexate; PBO, placebo; RA, rheumatoid arthritis; SDAl, Simplified Disease Activity Index.

Radiographic non-progression was the least limiting factor for achievement of CDC in our analyses, similar to other studies in patients treated with a combination of MTX and a TNF inhibitor. ${ }^{12}{ }^{41}$ This may be due to blockage of local TNF- $\alpha$ production and subsequent inflammatory response with TNF inhibitors compared with MTX alone. ${ }^{41}$ Notably, rapid radiographic progressors were seen in our study; however, absolute numbers were low, limiting conclusions.

A targeted treatment approach in OPTIMA (aimed at stable LDA at 6 months) enabled 24\% of MTX-IR patients to achieve CDC following an open-label adalimumab \pm MTX treatment for an additional year. In PREMIER, $25 \%$ of MTX-naive patients with early RA who were receiving initial treatment with the combination of adalimumab+MTX achieved CDC at year 1. Although the numbers of patients who achieved CDC in PREMIER and DE019 may be lower than might have been achieved if these studies had allowed treatment adjustments for incomplete responders, the numbers indirectly support treat-to-target approaches to optimise long-term outcomes for patients with established as well as early RA disease. ${ }^{13}$ 
The notable finding that achievement of remission at approximately 6 months was associated with CDC at 1 year is in line with the strong association between early treatment response and subsequent long-term remission that has been well documented in studies of patients with RA. ${ }^{14-1642}$ Although no single response measure can reflect the full burden of RA, CDC provides a stringent and comprehensive assessment of patient outcomes following treatment; furthermore, remission as a sole outcome does reflect CDC. The components of CDC impact each other; for example, it has been demonstrated that joint damage is a consequence of disease activity and irreversible impairment of physical function a consequence of joint damage ${ }^{43-45}$ Disability is also a consequence of both the current (reversible component) and past (irreversible component) disease activity, again highlighting the importance of achieving remission. Achievement of CDC has been associated with clinically meaningful improvements for patients in work-related outcomes, health-related quality of life, pain and fatigue ${ }^{7}$; stringent remission is similarly associated with significant improvements in health-related quality of life and physical function. ${ }^{46}$ Thus, the potential for remission to identify patients likely to achieve CDC has important implications for disease management. Although there is evidence suggesting that an earlier time to remission is the strongest predictor of sustained response/remission in patients with $\mathrm{RA},{ }^{47}{ }^{48}$ prospective clinical trials are needed to determine whether it will also be the strongest predictor of CDC.

The key limitation of the current report is that these were post hoc analyses of three individual clinical trials; however, although population differences prevented pooling of data, results were consistent among the trials. Nonetheless, the findings suggest that the current approach to comprehensive treatment deserves further study. Another limitation is that, although the components of CDC are established outcomes in clinical trials, the definition of CDC we used is not validated but is derived from treat-to-target recommendations. Debate remains regarding appropriate cut-off values for DAS28(CRP) ${ }^{13}$ defined in this study as $<2.6$ and $\leq 3.2$ for remission and LDA, respectively; SDAI was also examined because it has a validated cut-off for remission. ${ }^{49}{ }^{50}$ Furthermore, addition of a workplace or social participation assessment as a component of CDC may be warranted in future studies. ${ }^{42}{ }^{51}$ In addition, the low number of patients was an issue in certain subgroup analyses among patients who achieved remission at week 24 or 26 .

In conclusion, CDC appears to be a realistic treatment goal for many patients with early RA and established RA, and treatment with adalimumab+MTX appears to increase the likelihood of CDC. Achievement of remission at week 24 or 26 is associated with subsequent achievement of CDC at 1 year and thus may help guide treatment decisions.

\section{Author affiliations}

'Department of Rheumatology, University of Toronto, Toronto, Ontario, Canada ${ }^{2}$ Department of Rheumatology, Leiden University Medical Center, Leiden, The Netherlands

${ }^{3}$ Department of Clinical Immunology and Rheumatology, Academic Medical Center, Amsterdam, The Netherlands

${ }^{4}$ Department of Rheumatology, VU University Medical Center, Amsterdam, The Netherlands

${ }^{5}$ University of Leeds and NIHR Leeds Musculoskeletal Biomedical Research Unit, Leeds Institute of Rheumatic and Musculoskeletal Medicine, Leeds, UK

${ }^{6}$ Division of Rheumatology, Department of Medicine III, Medical University of Vienna, Vienna, Austria

${ }^{7}$ Second Department of Medicine, Hietzing Hospital, Vienna, Austria

${ }^{8}$ Global Medical Affairs, AbbVie Ltd, Cambridge, UK

${ }^{9}$ Global Medical Affairs, AbbVie NDL, Amsterdam, The Netherlands

${ }^{10}$ Pharmaceutical Development, AbbVie Deutschland GmbH \& Co. KG

Ludwigshafen, Germany

${ }^{11}$ Data and Statistical Sciences, AbbVie Inc, North Chicago, Illinois, USA

${ }^{12}$ Department of Rheumatology, University of California San Diego, La Jolla, California, USA

Contributors All authors participated in the interpretation of data, the preparation, review, and approval of the manuscript, and the decision to submit for publication.

Funding The studies were supported by AbbVie Inc. AbbVie funded studies DE019 (NCT00195702), PREMIER (NCT00195663), and OPTIMA (NCT00420927), contributed to their design, and was involved in the collection, analysis, and interpretation of the data, and in the writing, review, and approval of the manuscript. The authors thank Shufang Liu for contributing to the statistical analysis. Medical writing support was provided by Kathleen V. Kastenholz, PharmD, MS, of AbbVie and Maria Hovenden, PhD, of Complete Publication Solutions, LLC, North Wales, PA, and was funded by AbbVie.

Competing interests ECK has received research grants, consulting fees and/ or speaker fees from AbbVie, Amgen, AstraZeneca, Baylis Medical, Biotest, BMS, Genentech, Janssen, Lilly, Novartis, Nycomed, Pfizer, Roche, Sanofi-Aventis and UCB. FCB has received consulting fees from AbbVie, Amgen/Wyeth, Centocor and Schering-Plough. DH has received research grants and consulting fees from AbbVie, Amgen, AstraZeneca, BMS, Centocor, Chugai, Daiichi, Eli Lilly, GSK, Janssen Biologics, Merck, Novartis, Novo-Nordisk, Otsuka, Pfizer, Roche, Sanofi-Aventis, Schering-Plough, UCB, and Vertex, and is the Director of Imaging Rheumatology BV. RFV has received research grants and/or consulting fees from AbbVie, Biotest BMS, GSK, Janssen, Lilly, Merck, Pfizer, Roche, UCB and Vertex. PE has received research grants and/or consulting fees from AbbVie, BMS, Lilly, Merck, Novartis, Pfizer, Roche, Sandoz and UCB. IS, SF, HK and KC are full-time employees of AbbVie and may hold stock and/or options. JSS has received research grants, consulting fees and speaker fees from AbbVie, Amgen, AstraZeneca, BMS, Celgene, CentocorJanssen, Glaxo, Lilly, Pfizer (Wyeth), MSD (Schering-Plough), Novo-Nordisk, Roche, Sandoz and UCB. AK has received research grants and consulting fees from AbbVie, Amgen, AstraZeneca, BMS, Celgene, Centocor-Janssen, Pfizer, Roche and UCB.

Ethics approval This was a secondary analysis of three multicentre studies and as noted in the original publications, an institutional review board or ethics committee approved the studies at each site.

Provenance and peer review Not commissioned; externally peer reviewed.

Data sharing statement The datasets used and/or analysed during the current study can be requested from AbbVie.

Open Access This is an Open Access article distributed in accordance with the Creative Commons Attribution Non Commercial (CC BY-NC 4.0) license, which permits others to distribute, remix, adapt, build upon this work non-commercially, and license their derivative works on different terms, provided the original work is properly cited and the use is non-commercial. See: http://creativecommons.org/ licenses/by-nc/4.0/

(c) Article author(s) (or their employer(s) unless otherwise stated in the text of the article) 2017. All rights reserved. No commercial use is permitted unless otherwise expressly granted.

\section{REFERENCES}

1. Sangha O. Epidemiology of rheumatic diseases. Rheumatology 2000;39(Suppl 2):3-12.

2. van der Heijde DM, van Leeuwen MA, van Riel PL, et al. Radiographic progression on radiographs of hands and feet 
during the first 3 years of rheumatoid arthritis measured according to Sharp's method (van der Heijde modification). J Rheumatol 1995;22:1792-6.

3. Lindqvist $\mathrm{E}$, Jonsson $\mathrm{K}$, Saxne T, et al. Course of radiographic damage over 10 years in a cohort with early rheumatoid arthritis. Ann Rheum Dis 2003;62:611-6.

4. Aletaha D, Smolen J, Ward MM. Measuring function in rheumatoid arthritis: Identifying reversible and irreversible components. Arthritis Rheum 2006;54:2784-92.

5. Emery P, Breedveld FC, Dougados M, et al. Early referral recommendation for newly diagnosed rheumatoid arthritis: evidence based development of a clinical quide. Ann Rheum Dis 2002;61:290-7.

6. Smolen JS, Aletaha D, Bijlsma JW, et al. Treating rheumatoid arthritis to target: recommendations of an international task force. Ann Rheum Dis 2010;69:631-7.

7. Emery P, Kavanaugh A, Bao Y, et al. Comprehensive disease control (CDC): what does achieving CDC mean for patients with rheumatoid arthritis? Ann Rheum Dis 2015;74:2165-74.

8. Aletaha D, Strand V, Smolen JS, et al. Treatment-related improvement in physical function varies with duration of rheumatoid arthritis: a pooled analysis of clinical trial results. Ann Rheum Dis 2008;67:238-43.

9. Schoels M, Knevel R, Aletaha D, et al. Evidence for treating rheumatoid arthritis to target: results of a systematic literature search. Ann Rheum Dis 2010;69:638-43.

10. Knevel R, Schoels M, Huizinga TW, et al. Current evidence for a strategic approach to the management of rheumatoid arthritis with disease-modifying antirheumatic drugs: a systematic literature review informing the EULAR recommendations for the management of rheumatoid arthritis. Ann Rheum Dis 2010;69:987-94.

11. van der Heijde D, Breedveld FC, Kavanaugh A, et al. Disease activity, physical function, and radiographic progression after longterm therapy with adalimumab plus methotrexate: 5-year results of PREMIER. J Rheumatol 2010;37:2237-46.

12. Goekoop-Ruiterman YP, de Vries-Bouwstra JK, Allaart CF, et al. Clinical and radiographic outcomes of four different treatment strategies in patients with early rheumatoid arthritis (the Best study): a randomized, controlled trial. Arthritis Rheum 2005;52:3381-90.

13. Smolen JS, Landewé R, Breedveld FC, et al. EULAR recommendations for the management of rheumatoid arthritis with synthetic and biological disease-modifying antirheumatic drugs: 2013 update. Ann Rheum Dis 2014;73:492-509.

14. Barnabe C, Homik J, Barr SG, et al. The effect of different remission definitions on identification of predictors of both point and sustained remission in rheumatoid arthritis treated with anti-TNF therapy. $J$ Rheumatol 2014;41:1607-13.

15. Aletaha D, Funovits J, Keystone EC, et al. Disease activity early in the course of treatment predicts response to therapy after one year in rheumatoid arthritis patients. Arthritis Rheum 2007:56:3226-35.

16. Verstappen SM, van Albada-Kuipers GA, Bijlsma JW, et al. A good response to early DMARD treatment of patients with rheumatoid arthritis in the first year predicts remission during follow up. Ann Rheum Dis 2005;64:38-43.

17. Keystone EC, Kavanaugh AF, Sharp JT, et al. Radiographic, clinical, and functional outcomes of treatment with adalimumab (a human anti-tumor necrosis factor monoclonal antibody) in patients with active rheumatoid arthritis receiving concomitant methotrexate therapy: a randomized, placebo-controlled, 52-week trial. Arthritis Rheum 2004;50:1400-11

18. Breedveld FC, Weisman MH, Kavanaugh AF, et al. The PREMIER study: a multicenter, randomized, double-blind clinical trial of combination therapy with adalimumab plus methotrexate versus methotrexate alone or adalimumab alone in patients with early, aggressive rheumatoid arthritis who had not had previous methotrexate treatment. Arthritis Rheum 2006;54:26-37.

19. Kavanaugh A, Fleischmann RM, Emery P, et al. Clinical, functional and radiographic consequences of achieving stable low disease activity and remission with adalimumab plus methotrexate or methotrexate alone in early rheumatoid arthritis: 26-week results from the randomised, controlled OPTIMA study. Ann Rheum Dis 2013;72:64-71.

20. Smolen JS, Emery P, Fleischmann R, et al. Adjustment of therapy in rheumatoid arthritis on the basis of achievement of stable low disease activity with adalimumab plus methotrexate or methotrexate alone: the randomised controlled OPTIMA trial. Lancet 2014;383:321-32

21. Arnett FC, Edworthy SM, Bloch DA, et al. The American Rheumatism Association 1987 revised criteria for the classification of rheumatoid arthritis. Arthritis Rheum 1988;31:315-24.
22. Soubrier M, Zerkak D, Gossec L, et al. Which variables best predict change in rheumatoid arthritis therapy in daily clinical practice? $J$ Rheumatol 2006;33:1243-6.

23. Fransen J, van Riel PL. The Disease Activity Score and the EULAR response criteria. Clin Exp Rheumatol 2005;23(5 Suppl 39):S93-9.

24. Singh JA, Furst DE, Bharat $A$, et al. 2012 update of the 2008 American College of Rheumatology recommendations for the use of disease-modifying antirheumatic drugs and biologic agents in the treatment of rheumatoid arthritis. Arthritis Care Res 2012:64:625-39.

25. Shammas RM, Ranganath VK, Paulus HE. Remission in rheumatoid arthritis. Curr Rheumatol Rep 2010;12:355-62.

26. Smolen JS, Breedveld FC, Schiff MH, et al. A simplified disease activity index for rheumatoid arthritis for use in clinical practice. Rheumatology 2003;42:244-57.

27. Prevoo ML, van't Hof MA, Kuper HH, et al. Modified disease activity scores that include twenty-eight-joint counts. development and validation in a prospective longitudinal study of patients with rheumatoid arthritis. Arthritis Rheum 1995;38:44-8.

28. van Gestel AM, Haagsma CJ, van Riel PL. Validation of rheumatoid arthritis improvement criteria that include simplified joint counts. Arthritis Rheum 1998;41:1845-50.

29. Fries JF, Spitz PW, Young DY. The dimensions of health outcomes: the health assessment questionnaire, disability and pain scales. $J$ Rheumatol 1982;9:789-93.

30. Felson DT, Smolen JS, Wells G, et al. American College of Rheumatology/European League against rheumatism provisional definition of remission in rheumatoid arthritis for clinical trials. Ann Rheum Dis 2011;70:404-13.

31. Hochberg MC, Chang RW, Dwosh I, et al. The American College of Rheumatology 1991 revised criteria for the classification of global functional status in rheumatoid arthritis. Arthritis Rheum 1992;35:498-502.

32. van der Heijde D. How to read radiographs according to the sharp/ van der heijde method. J Rheumatol 1999;26:743-5.

33. Sharp JT, Lidsky MD, Collins LC, et al. Methods of scoring the progression of radiologic changes in rheumatoid arthritis. correlation of radiologic, clinical and laboratory abnormalities. Arthritis Rheum 1971;14:706-20

34. Plant MJ, Saklatvala J, Borg AA, et al. Measurement and prediction of radiological progression in early rheumatoid arthritis. $J$ Rheumatol 1994:21:1808-13.

35. van der Heijde D, Simon L, Smolen J, et al. How to report radiographic data in randomized clinical trials in rheumatoid arthritis: guidelines from a roundtable discussion. Arthritis Rheum 2002;47:215-8.

36. Klareskog L, van der Heijde D, de Jager JP, et al. Therapeutic effect of the combination of etanercept and methotrexate compared with each treatment alone in patients with rheumatoid arthritis: doubleblind randomised controlled trial. Lancet 2004;363:675-81.

37. Lipsky PE, van der Heijde DM, St Clair EW, et al. Infliximab and methotrexate in the treatment of rheumatoid arthritis. anti-tumor necrosis factor trial in rheumatoid arthritis with concomitant therapy study group. N Engl J Med 2000;343:1594-602.

38. Klarenbeek NB, Koevoets R, van der Heijde DM, et al. Association with joint damage and physical functioning of nine composite indices and the 2011 ACR/EULAR remission criteria in rheumatoid arthritis. Ann Rheum Dis 2011;70:1815-21.

39. Gaujoux-Viala C, Mouterde G, Baillet A, et al. Evaluating disease activity in rheumatoid arthritis: which composite index is best? a systematic literature analysis of studies comparing the psychometric properties of the DAS, DAS28, SDAI and CDAl. Joint Bone Spine 2012;79:149-55.

40. Fleischmann R, van der Heijde D, Koenig AS, et al. How much does disease activity score in 28 joints ESR and CRP calculations underestimate disease activity compared with the simplified disease activity index? Ann Rheum Dis 2015;74:1132-7.

41. Smolen JS, Van Der Heijde DM, St Clair EW, et al. Predictors of joint damage in patients with early rheumatoid arthritis treated with highdose methotrexate with or without concomitant infliximab: results from the ASPIRE trial. Arthritis Rheum 2006;54:702-10.

42. Verschueren P, Esselens G, Westhovens R. Predictors of remission, normalized physical function, and changes in the working situation during follow-up of patients with early rheumatoid arthritis: an observational study. Scand J Rheumatol 2009;38:166-72.

43. Combe B, Cantagrel A, Goupille P, et al. Predictive factors of 5-year health assessment questionnaire disability in early rheumatoid arthritis. J Rheumatol 2003;30:2344-9.

44. Drossaers-Bakker KW, de Buck M, van Zeben D, et al. Long-term course and outcome of functional capacity in rheumatoid arthritis: the effect of disease activity and radiologic damage over time. Arthritis Rheum 1999;42:1854-60. 
45. Welsing PM, van Gestel AM, Swinkels HL, et al. The relationship between disease activity, joint destruction, and functional capacity over the course of rheumatoid arthritis. Arthritis Rheum 2001;44:2009-17.

46. Radner H, Smolen JS, Aletaha D. Remission in rheumatoid arthritis: benefit over low disease activity in patient-reported outcomes and costs. Arthritis Res Ther 2014;16:R56.

47. Kuriya B, Xiong J, Boire G, et al. Earlier time to remission predicts sustained clinical remission in early rheumatoid arthritis--results from the Canadian Early Arthritis Cohort (CATCH). J Rheumatol 2014;41:2161-6.
48. Schipper LG, Fransen J, den Broeder AA, et al. Time to achieve remission determines time to be in remission. Arthritis Res Ther 2010;12:R97.

49. Aletaha D, Smolen J. The Simplified Disease Activity Index (SDAI) and the Clinical Disease Activity Index (CDAl): a review of their usefulness and validity in rheumatoid arthritis. Clin Exp Rheumatol 2005;23(5 Suppl 39):S100-8.

50. Aletaha D, Ward MM, Machold KP, et al. Remission and active disease in rheumatoid arthritis: defining criteria for disease activity states. Arthritis Rheum 2005;52:2625-36.

51. Benka J, Nagyova I, Rosenberger J, et al. Social participation in early and established rheumatoid arthritis patients. Disabil Rehabil 2016;38:1172-9. 